\title{
INRG Stage M
}

National Cancer Institute

\section{Source}

National Cancer Institute. INRG Stage M. NCI Thesaurus. Code C133430.

Neuroblastoma with distant metastatic disease (except MS). 